\title{
Peripheral Cement Ossifying Fibroma: A Case Report and Review of Literature
}

\author{
Ankur Kanodia', Shalini Jaiman², Ragini Kanodia ${ }^{3}$, Rakesh Garg ${ }^{4}$ \\ ${ }^{1}$ Final year MDS, Department of Periodontology and Implantology, NIMS Dental College and Hospital, Jaipur, Rajasthan, India. \\ 2Final year MDS, Department of Oral and Maxillofacial Pathology, Ahmedabad Dental College, Ahmedabad, Gujrat, India. \\ ${ }^{3}$ Senior Resident, Department of obstetrics and gynaecology, SMS Medical College \& Hospital , Jaipur, Rajasthan, India. \\ ${ }^{4}$ Senior Resident, Dept. of Dentistry, S.P Medical College, Bikaner, Rajasthan, India.
}

\begin{abstract}
Peripheral cemento-ossifying fibroma is frequently occurring over growth in anterior maxillae and is a reactive in nature. It should be excised as soon as possible as it is a slow-growing benign tumor which may lead to pathologic migration and other periodontal problems. It comprises about $9 \%$ of all gingival overgrowths. It is commonly seen in second and third decade of life with female prediction. It has a recurrence rate of $8 \%$ to $20 \%$, so a close postoperative follow-up is also required. Herein, we are reporting a case of peripheral cementoossifying fibroma in 56 year old female patient. Excisional biopsy was carried out and diagnosis was done histopathologically.
\end{abstract}

Keywords: Peripheral cement-ossifying fibroma, Cementum, Gingiva.

\section{INTRODUCTION}

The localized reactive lesions occuring on the gingiva, includes focal fibrous hyperplasia, pyogenic granuloma, peripheral giant cell granuloma and peripheral cemento-ossifying fibroma [PCOF]'. Benign fibrous overgrowths arising from the mucous membrane are termed as 'fibromas'. Fibromas are frequent growths in the oral cavity; arising due to overproduction of fibrous tissue in the connective tissue. It usually represents a reactive focal fibrous hyperplasia due to trauma or local irritation². Cemento-ossifying fibroma is a relative rare lesion considered as an osteogenic tumor (nonodontogenic) with variable expressiveness. It is defined as a well-demarcated and occasionally encapsulated lesion consisting of fibrous tissue containing variable amounts of mineralized material resembling bone (ossifying fibroma), cementum (cementifying fibroma), or both ${ }^{3}$.

PCOF accounts for $3.1 \%$ of all oral tumors ${ }^{4}$ and for $9.6 \%$ of gingival lesions ${ }^{5}$. The pathogenesis of this tumor is uncertain, due to their clinical and histopathological similarities, some PCOFs are believed to develop fibrous maturation and subsequent calcification. PCOF is frequently associated with irritant agents such as calculus, bacterial plaque, orthodontic appliances, ill adapted crowns, and irregular restorations. The mineralized product probably originates from periosteal cells or from the periodontal ligament 6 . PCOF affects both genders, but a higher predilection for females has been reported in the literature 4 and respect to race, there is a predominance in Whites $(71 \%)$ compared to Blacks $(36 \%)^{7}$. It may occur at any range, but exhibits a peak incidence between the second ${ }^{8}$ and third decades $^{7}$. Clinically, PCOF's are sessile or pedunculated, usually

\section{*Correspondance to}

Dr Ankur Kanodia, Final year MDS, Department of Periodontology and Implantology, NIMS Dental College and Hospital, Jaipur.

Email: kanodiahospital@gmail.com

Article History:

Received: 02-05-2016, Revised: 10-05-2016, Accepted: 20-05-2016

\begin{tabular}{|l|c|}
\hline \multicolumn{2}{|c|}{ Access this article online } \\
\hline Website: & Quick Response code \\
www.jmrp.com & \\
\hline DOI: & \\
10.21276/jmrp.2016.2.3.048 & \\
\hline
\end{tabular}

ulcerated, and erythematous or exhibiting a color similar to the surrounding gingiva. Most lesions are $<2 \mathrm{~cm}$ in size, although larger ones occasionally occur ${ }^{1}$.

\section{CASE REPORT}

A 60 year old female came with a chief complaint of swollen gums in lower anterior region. On clinical examination the swelling was seen over attached gingiva of 32,33 region. There was fixed partial denture in relation to 33 to 42 . The swelling was pinkish in colour, smooth in texture and firm on palpation. It was approximately measuring $2 \mathrm{~cm} \times 1 \mathrm{~cm}$ [Fig.1]. Based on clinical findings it was diagnosed as pyogenic granuloma. Later patient was adviced for radiological and hematological investigations. OPG (Orthopantamo graph) was taken which revealed that there was severe bone loss in relation to 33 and 42, apart from this there was well circumscribed radiolucency pertained to roots of 36 [Fig.2]. There were no abnormalities in hematological investigations. Based on the radiological and clinical findings the lesion was thought to be benign and planned for excision. After excision the specimen was sent for histopathological examination. Extraction of 46 was also done after extraction there was blood mixed with pus drained from the extracted socket. H\&E sections showed epithelium and connective tissue connective tissue is fibrocellular with spindle shaped fibroblasts. There was also presence of hemtoxyphillic osteiod and round to oval shaped cementum like calcifications [Fig.3]. Correlating clinically and histopathologically it was finally diagnosed as peripheral cementoossifying fibroma. 


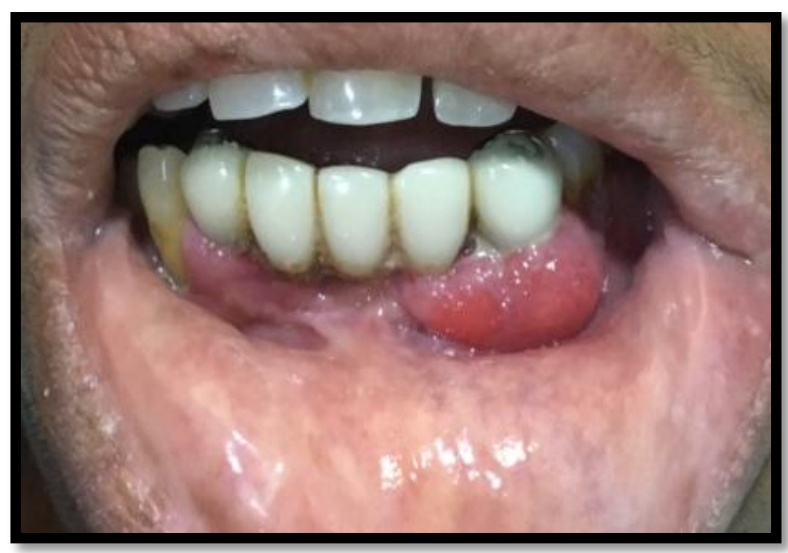

Fig 1: Clinical image showing extension of lesion

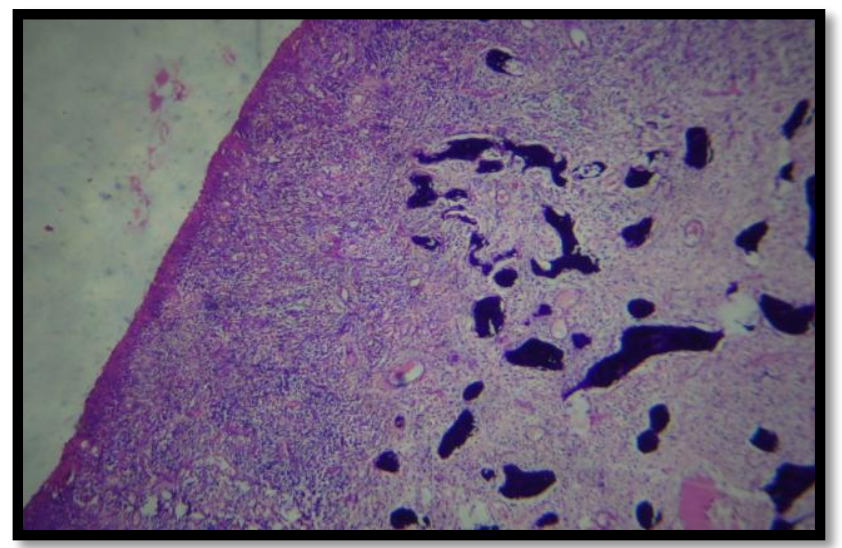

Fig 3: Osteoid and Cemetum like calcifications in the connective tissue

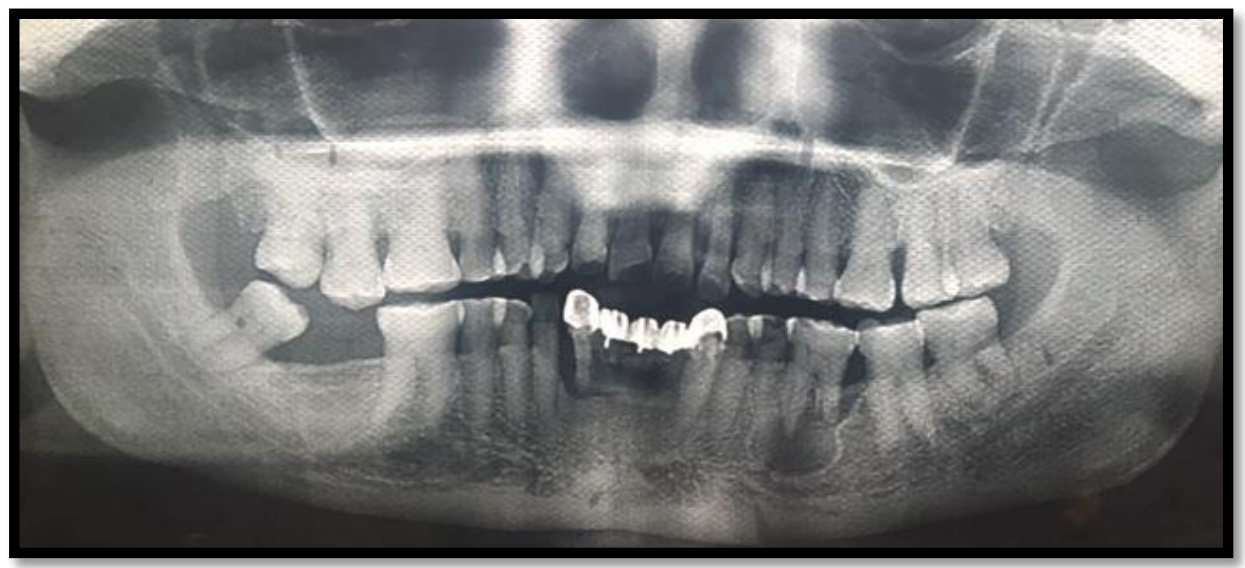

Fig 2: OPG showing bone loss in lower anterior region and well demarcated radiolucency apical to 36

\section{DISCUSSION}

Peripheral ossifying fibroma is thought to be either reactive or neoplastic in nature. There is considerable confusion in the nomenclature of peripheral ossifying fibroma, because it being called by several names, such as peripheral cementifying fibroma, ossifying fibroepithelial polyp, peripheral fibroma with osteogenesis, peripheral fibroma with cementogenesis, peripheral fibroma with calcification, calcifying or ossifying fibroma epulis, and calcifying fibroblastic granuloma ${ }^{9}$. Ossifying fibromas exhibit, bone, cementum and spheroidal calcifications, because of which various nomenclature was given to this benign fibroosseous neoplasms. The term ossifying is given when bone predominates within the lesion, whereas term "cementifying" is assigned when curvilinear trabeculae or spheroidal calcifications are present ${ }^{10}$. When bone and cementum-like tissues are observed, the lesions have been referred to as cemento-ossifying fibroma ${ }^{10}$. Clinically and radiographically cemento-ossifying fibromas are difficult to be distinguished from ossifying fibromas ${ }^{11}$. Endo et al. conducted a immunohistochemical study in order to distinguish cementifying fibroma from ossifying fibromas and fibrous dysplasias by using keratin sulfate and chondrotoin-4 sulfate of which the cementifying fibromas showed significant immunoreactivity for keratan sulfate whereas ossifying fibromas, and fibrous dysplasia showed intensive immunostaining for chondroitin-4-sulfate ${ }^{11}$.

The term cemento-ossifying has been referred to as age old term and scientifically inappropriate because the clinical presentation and histopathology of cemento-ossifying fibroma are the same in areas where there is no cementum, such as the skull, femur, and tibia. These are all ossifying fibromas; those that happen to occur in the jaws should not be termed cement ossifying fibromas merely because of the presence of teeth. Moreover, there is no histologic or biochemical difference between cementum and bone. Cemento-ossifying fibroma is the term given mainly due to presence of dysmorphic round basophilic bone particles within ossifying fibroma, which have arbitrarily been called cementicles. However, these so-called cementicles are not from cementum but instead represent a dysmorphic product of this tumour analogous to the keratin pearls, which are a dysmorphic product of squamous cell carcinoma ${ }^{12}$.

Though the etiopathogenesis of peripheral ossifying fibroma is uncertain, they were thought to be originated from cells of periodontal ligament 9 . The reasons to substantiate periodontal ligament origin include, its occurrence predominantly in the gingiva (interdental papilla), the proximity of gingiva to the periodontal ligament, and the presence of oxytalan fibres within the mineralized matrix of some lesions ${ }^{9}$. Excessive proliferation of mature fibrous connective tissue is a response to gingival injury, gingival irritation, subgingival calculus, or a foreign body in the gingival sulcus. Chronic irritation of the periosteal and periodontal membrane causes metaplasia of the connective tissue and resultant initiation of formation of bone or dystrophic calcification. It has been suggested that the lesion may be caused by fibrosis of the granulation tissue ${ }^{13}$.

Lesions involving the gingival soft tissues are rare compared to the lesions appearing within bone ${ }^{11}$. Mesquita RA found higher numbers of argyrophilic nucleolar organizer regions (AgNORs) and proliferating cell nuclear antigen- (PCNA-) positive cells in ossifying fibroma than in peripheral ossifying fibroma, indicating 
higher proliferative activity in ossifying fibroma ${ }^{14}$. X-ray diffraction analysis indicated that the mineral phase of both central and peripheral tissues consists of apatite crystals and that the crystallinity of the apatites might improve progressively with the development of the lesion, possibly to the same degree as that of bone apatite ${ }^{15}$. Peripheral ossifying fibroma tends to occur in the 2nd and 3rd decades of life, with peak prevalence between the ages of 10 and 19 but in the present case it was seen in 60 year old female.

Eversole and Rovin ${ }^{16}$ stated the similar sex and site predilection of pyogenic granuloma. Gardner ${ }^{17}$ stated that peripheral ossifying fibroma, cellular connective tissue is so characteristic that a histologic diagnosis can be made with confidence, regardless of the presence or absence of calcification. Buchner and Hansen ${ }^{18}$ hypothesized that early POF presents as ulcerated nodules with little calcification, allowing easy misdiagnosis as a pyogenic granuloma. The POF must be differentiated from the peripheral odontogenic fibroma (PODF) described by the World Health Organization ${ }^{17,18}$. Histologically, the PODF has been defined as a fibroblastic neoplasm containing odontogenic epithelium ${ }^{19}$. Despite a preponderance of the literature supporting differentiation, some authors continue to argue that the POF (or peripheral cemento-ossifying fibroma) is the peripheral counterpart of the central cemento-ossifying fibroma ${ }^{20}$. The POF, as discovered in this case, is a focal, reactive, nonneoplastic tumour-like growth of soft tissue often arising from the interdental papilla ${ }^{18}$. It is a fairly common lesion, comprising nearly $3 \%$ of oral lesions biopsied in 1 study 1 approximately $1 \%-2 \%$ in other studies $^{20}$. In 1993, S. Das and A. Das ${ }^{8}$ obtained similar results, with 1.6\% POFs among 2,370 intraoral biopsies.

POFs are believed to arise from gingival fibers of the periodontal ligament as hyperplastic growth of tissue that is unique to the gingival mucosa16,17. This hypothesis is based on the fact that POFs arise exclusively on the gingiva, the subsequent proximity of the gingiva to the periodontal ligament, and the inverse correlation between age distribution of patients presenting with POF and the number of missing teeth with associated periodontal ligament ${ }^{19}$. The POF lesion is generally small and does not require imaging beyond radiographs ${ }^{17}$. Treatment consists of conservative surgical excision $^{19}$ and scaling of adjacent teeth ${ }^{17}$. Therefore, regular follow-up is required. Although peripheral ossifying fibroma is benign, reactive lesion, the recurrence rate is fairly high. Therefore, the patients are still under follow-up period.

\section{CONCLUSION}

POF is a slowly progressing lesion, the growth of which is generally limited. Many cases will progress for long periods before patients seek treatment because of the lack of symptoms associated with the lesion. A slowly growing pink soft-tissue nodule should raise suspicion of a POF. Close postoperative follow-up is required because of the growth potential of incompletely removed lesions and the $8 \%-20 \%$ recurrence rate. In the present case post-operative follow-up was done for a period of one year which was uneventful.

\section{REFERENCES}

1. Sah K, Kale AD, Hallikerimath $S$, Chandra S. Peripheral cementoossifying fibroma: Report of a recurrence case. Contemporary Clinical Dentistry. 2012;3(Suppl1):S23-S25.

2. Antony VV, Khan R. Peripheral Cemento- Ossifying Fibroma-A Case Report. IOSR Journal of Dental and Medical Sciences.2013;6(3):34-37.
3. Kiran Kumar Ganji, ArunKumar Bhimashankar Chakki, Sharanbasappa Chandrashekar Nagaral, and Esha Verma, "Peripheral Cemento-Ossifying Fibroma: Case Series Literature Review," Case Reports in Dentistry, 2013, vol. 2013, Article ID 930870, 5 pages.

4. J. N. Kenney, G. E. Kaugars, and L. M. Abbey, "Comparison between the peripheral ossifying fibroma and peripheral odontogenic fibroma," Journal of Oral and Maxillofacial Surgery, 1989, 47(4), pp. 378-382.

5. J. D. Walters, J. K. Will, R. D. Hatfield, D. A. Cacchillo, and D. A. Raabe, "Excision and repair of the peripheral ossifying fibroma: a report of 3 cases," Journal of Periodontology, 2001, vol. 72, no. 7, pp. 939-944.

6. D. A. Orkin and V. D. Amaidas, "Ossifying fibrous epulis. an abbreviated case report," Oral Surgery, Oral Medicine, Oral Pathology, 1984, vol. 57, no. 2, pp. 147-148.

7. Z. E. S. Cuisia and R. B. Brannon, "Peripheral ossifying fibroma-a clinical evaluation of 134 pediatric cases," Pediatric Dentistry, 2001, vol. 23, no. 3, pp. 245-248.

8. S. Das and A. K. Das, "A review of pediatric oral biopsies from a surgical pathology service in a dental school," Pediatric Dentistry, 1993, vol. 15, no. 3, pp. 208-211.

9. S. K. Kumar, S. Ram, M. G. Jorgensen, C. F. Shuler, and P. P. Sedghizadeh, "Multicentric peripheral ossifying fibroma," Journal of oral science, 2006, vol. 48, no. 4, pp. 239-243.

10. L. R. Eversole, A. S. Leider, and K. Nelson, "Ossifying fibroma: a clinicopathologic study of sixty-four cases," Oral Surgery Oral Medicine and Oral Pathology, 1985, vol. 60, no. 5, pp. 505-511.

11. Y. Endo, K. Uzawa, Y. Mochida et al., "Differential distribution of glycosaminoglycans in human cementifying fibroma and fibro-osseous lesions," Oral Diseases, 2003, vol. 9, no. 2, pp. 73-76.

12. RE Marx, D Stern, Oral And Maxillofacial Pathology: A RationAle for Diagnosis and treatment, Quintessence Publishing, 2003, III, USA.

13. F. Kendrick and W. F. Waggoner, "Managing a peripheral ossifying fibroma," Journal of Dentistry for Children, 1996, 63(2), pp. 135-138.

14. R. A. Mesquita, S. C. Orsini, M. Sousa, and N. S. De Araújo, "Proliferative activity in peripheral ossifying fibroma and ossifying fibroma," Journal of Oral Pathology and Medicine, 1998, vol. 27, no. 2, pp. 64-67. 15. T Aoba, C Yoshioka, Y Ogawa, T Yagi. A study of the mineral phase of cementifying fibroma, Journal of Oral Pathology, 1978,7(3),156-161.

16. L. R. Eversole and S. Rovin, "Reactive lesions of the gingiva," Journal of oral pathology, 1972, vol. 1, no. 1, pp. 30-38.

17. D. G. Gardner, "The peripheral odontogenic fibroma: an attempt at clarification," Oral Surgery Oral Medicine and Oral Pathology, 1982, vol. 54 , no. 1, pp. 40-48.

18. A. Buchner and L. S. Hansen, "The histomorphologic spectrum of peripheral ossifying fibroma," Oral Surgery Oral Medicine and Oral Pathology, 1987, vol. 63, no. 4, pp. 452-461.

19. J. N. Kenney, G. E. Kaugars, and L. M. Abbey, "Comparison between the peripheral ossifying fibroma and peripheral odontogenic fibroma," Journal of Oral and Maxillofacial Surgery, 1989, 47(4), pp. 378-382.

20. L. Feller, A. Buskin, and E. J. Raubenheimer, "Cemento-ossifying fibroma: case report and review of the literature," Journal of the International Academy of Periodontology, 2004, 6(4), pp. 131-135.

\section{Source of Support: Nil. Conflict of Interest: None Declared.}

Copyright: (c) the author(s) and publisher. IJMRP is an official publication of Ibn Sina Academy of Medieval Medicine \& Sciences, registered in 2001 under Indian Trusts Act, 1882.

This is an open access article distributed under the terms of the Creative Commons Attribution Non-commercial License, which permits unrestricted non-commercial use, distribution, and reproduction in any medium, provided the original work is properly cited.

Cite this article as: Ankur Kanodia, Shalini Jaiman, Ragini Kanodia, Rakesh Garg. Peripheral Cement Ossifying Fibroma: A Case Report and Review of Literature. Int J Med Res Prof. 2016; 2(3):223-25. 